\title{
Active Stage of Autoimmune Diabetes Is Associated with the Expression of a Novel Cytokine, IGIF, Which Is Located Near Idd2
}

\author{
Helga Rothe, ${ }^{\star}$ Nancy A. Jenkins, ${ }^{\ddagger}$ Neal G. Copeland, ${ }^{\ddagger}$ and Hubert Kolb* \\ *Diabetes Research Institute at the Heinrich-Heine University Düsseldorf, University Düsseldorf, Düsseldorf D-40225, Germany; and \\ ${ }^{\ddagger}$ Mammalian Genetics Laboratory, ABL-Basic Research Program, National Cancer Institute-Frederick Cancer Research and \\ Development Institute, Frederick, Maryland 21702
}

\begin{abstract}
Recently, interferon-gamma-inducing-factor (IGIF) has been described as a novel monokine that is a more potent interferon- $\gamma($ IFN- $\gamma)$ inducer than IL-12. By cloning IGIF from affected tissue and studying IGIF gene expression, we describe for the first time a close association of this cytokine with an autoimmune disease.

The non-obese diabetic (NOD) mouse spontaneously develops autoimmune insulitis and diabetes which can be accelerated and synchronized by a single injection of cyclophosphamide. IGIF mRNA was demonstrated by reverse transcriptase PCR in NOD mouse pancreas during early stages of insulitis. Levels of IGIF mRNA increased rapidly after cyclophosphamide treatment and preceded a rise in IFN- $\gamma$ mRNA, and subsequently diabetes. Interestingly, these kinetics mimick that of IL-12p40 mRNA, resulting in a close correlation of individual mRNA levels.

Cloning of the IGIF cDNA from pancreas RNA followed by sequencing revealed identity with the IGIF sequence cloned from Kupffer cells and in vivo preactivated macrophages. When extending our study to macrophages of the spleen we observed that NOD mouse macrophages responded to cyclophosphamide with IGIF gene expression while macrophages from Balb/c mice treated in parallel did not. The IGIF gene position is located within the Idd2 interval on mouse chromosome 9 and therefore it is a candidate for the Idd 2 susceptible gene. We conclude that IGIF expression is abnormally regulated in autoimmune NOD mice and closely associated with diabetes development. (J. Clin. Invest. 1997. 99:469-474.) Key words: macrophages • NOD mouse $\cdot$ genomic mapping $\cdot$ IFN $-\gamma \cdot \mathrm{Th} 1 / \mathrm{Th} 2$-balance
\end{abstract}

\section{Introduction}

Interferon- $\gamma$ inducing factor (IGIF), ${ }^{1}$ was recently cloned from liver where it is expressed in Kupffer cells (1). IGIF augments natural killer activity in spleen cells and stimulates IFN- $\gamma$ pro-

Address correspondence to Helga Rothe, Ph.D., Diabetes Research Institute, Auf'm Hennekamp 65, D-40225 Düsseldorf, Germany. Phone: +49-211-3382641; FAX: +49-211-3382606.

Received for publication 5 August 1996 and accepted in revised form 2 December 1996.

1. Abbreviations used in this paper: $\mathrm{CY}$, cyclophosphamide; IGIF, interferon-gamma inducing factor; NOD, non-obese diabetic; PSL, ${ }^{32} \mathrm{P}$ stimulated luminescence; RT-PCR, reverse transcriptase PCR; Th1, T helper type 1; Th2, T helper type 2.

The Journal of Clinical Investigation

Volume 99, Number 3, February 1997, 469-474 duction in established T helper type 1 (Th1) cells (1). To date, studies of a positive role of this monokine in autoimmune disease has not been reported.

The non-obese diabetic (NOD) mouse, an animal model of type 1 diabetes, exhibits spontaneous mononuclear infiltration of several endocrine organs, including pancreatic islets. Inflammation of the endocrine pancreas is accompanied by the preferential loss of $\beta$ cells, eventually leading to insulin deficient diabetes. The disease process is asynchronous between individual islets and progresses to overt diabetes in $20-80 \%$ of mice, with a peak incidence between 3 and 6 mo of age $(2,3)$. Diabetes development in young animals can be accelerated and synchronized by a single injection of cyclophosphamide (CY). Concomitantly, a progression of islet inflammation from periinsulitis to destructive intrainsulitis is observed. Periinsulitis in general does not cause substantial $\beta$ cell destruction and is characterized by a dominance of IL-4 producing T cells (Th2 cells). The progression towards intrainsulitis is associated with the appearance of large numbers of IFN- $\gamma$ positive $\mathrm{T}$ cells (Th1 cells) $(4,5)$. The crucial role of Th1 cells in mediating $\beta$ cell destructive islet inflammation has been shown by the inhibitory effects of monoclonal antibodies to IFN- $\gamma$ (6) and by the ability of Th1-like but not Th2-like islet specific $\mathrm{T}$ cell clones to adoptively transfer diabetes (7).

We have proposed earlier that the progression to destructive Th1 dependent autoimmunity is mediated by an abnormal expression of Th1 inducing costimulatory factors by antigen presenting cells, such as IL-12 (8). Indeed, repeated injections of IL-12 (9) have been found to enhance diabetes development in NOD mice (10) and disruption of the IL-12 gene suppressed autoimmune diabetes in this mouse model (11). However, despite the absence of IL-12 production, a fraction of animals still developed insulin-deficient diabetes. To address the possible role of the newly described monokine IGIF in Th1-dependent autoimmunity, we tried to clone IGIF from NOD mouse pancreas lesions and undertook a study of IGIF gene expression in Th2 versus Th1-dominated disease stages.

\section{Methods}

Animals. Female Balb/cHan mice were obtained from the central animal facility of the Heinrich-Heine University of Düsseldorf (Düsseldorf, Germany). Female NOD/Bom mice were purchased from Bomholtgard Breeding Centre (Ry, Denmark) at 9 wk of age and maintained in our animal facility under conventional conditions with standard diet (Sniff, Soest, Germany) and tap water ad libitum. One group of mice remained untreated and another group was treated with CY $(250 \mathrm{mg} / \mathrm{kg}$ i.p. $)$ at $70 \mathrm{~d}$ of age. Urinary glucose analysis was done daily, hyperglycaemia was confirmed by blood glucose determination. Animals were regarded as diabetic when blood glucose levels were found above $16.7 \mathrm{mmol} / \mathrm{liter}(300 \mathrm{mg} / \mathrm{dl})$ as determined by hexokinase method. In the CY treated group first cases of diabetes were diagnosed 10-11 d after CY injection. Therefore, animals of this 
group were killed 1, 3, and $9 \mathrm{~d}$ after injection of CY. All untreated mice were killed at the age of 70-80 d. Mice were killed under anaesthesia for pancreas and spleen analysis. The principles of laboratory animal care were followed (NIH publication No. 85-23, revised 1985).

Isolation of adherent and non-adherent spleen cells. The spleen cells were excised under sterile conditions and each spleen was divided into two parts. One part of the spleen was used for isolation of RNA and the other for the preparation of a single cell suspension. Erythrocytes were lysed by 15 min incubation of spleen cells in lysis buffer (in mmol/liter:10 $\mathrm{KHCO}_{3}, 155 \mathrm{NH}_{4} \mathrm{Cl}, 0.1$ EDTA, pH 7.4) on ice. The cells were washed three times by centrifugation $\left(250 \mathrm{~g}, 10 \mathrm{~min}, 10^{\circ} \mathrm{C}\right)$ in PBS.

The spleen cell suspension was separated into adherent and nonadherent fractions by incubation in a plastic petri dish (RPMI 1640 plus $10 \%$ FCS (Gibco Europe, Heidelberg, Germany), $5 \% \mathrm{CO}_{2}$, $37^{\circ} \mathrm{C}$. After $1 \mathrm{~h}$ the non-adherent cells were washed off from the remaining adherent cells and collected by centrifugation. This procedure enriched macrophages more than $90 \%$ as demonstrated by indirect immunofluorescence (2) using monoclonal antibodies M1/70 (Dianova, Hamburg, Germany) and F4/80 (gift of S. Gordon, Oxford, UK). Before RNA extraction the cells were washed three times with PBS.

$m R N A$ analysis. Total RNA was isolated from fresh pancreatic or spleen tissue from adherent or non-adherent spleen cells by guanidinium thiocyanate-phenol-chloroform extraction. Determination and quantification of specific mRNA was performed by reverse transcriptase PCR (RT-PCR) as described in references 5 and 12. Specific primers for $\beta$-actin and IFN- $\gamma$ were purchased from Clontech (Palo Alto, CA). The specific primers for IGIF were as follows: 5'-primer: 5'-ACTGTACAACCGCAGTAATACGG-3'; 3'-primer: 5'-AGTGAACATTACAGATTTATCCC-3'. PCR products were subjected to electrophoresis on a $2 \%$ agarose gel followed by hybridization with specific ${ }^{32} \mathrm{P}$-labeled probes binding at the sites between the primer sequences. Signals were quantified by measuring the ${ }^{32} \mathrm{P}$ stimulated luminescence (PSL) by a phosphoimager. Relative PSL of IGIF was calculated by normalization the measured PSL to the strength of $\beta$-actin signal (5).

Cloning of the IGIF cDNA. Total RNA was extracted from the pancreas of a NOD mouse $3 \mathrm{~d}$ after treatment of the animal with $\mathrm{CY}$.
The full length cDNA was amplified with primers (5'-primer: $5^{\prime}$-CCGGAATTCATGGCTGCCATGTCAGAAGAC-3': 3'-primer: 5'-CCGGAATTCCTTTGATGTAAGTTAGTGAGAG-3') which enclose Eco RI restriction sites, by the method of RT-PCR. 5' - and 3'-primers should amplify the published full length cDNA (1). The amplified fragment was restricted by Eco RI and subcloned in the multicloning site of BluescriptII SK (+). The recombinant DNA (pKIGIF) was transformed in competent Escherichia coli JM105. The cDNA was sequenced by an automatic sequencer (model 373A; Applied Biosystems, Inc., Foster City, CA) from both directions. The cloned sequence was compared to the published sequence (1) by the program PC/GENE (Intelli Genetics, Inc., Mountain View, CA).

Interspecific mouse backcross mapping. Interspecific backcross progeny were generated by mating $(\mathrm{C} 57 \mathrm{BL} / 6 \mathrm{~J} \times$ Muridae spretus $) \mathrm{F}_{1}$ females and $\mathrm{C} 57 \mathrm{BL} / 6 \mathrm{~J}$ males as described in reference 13 . A total of $205 \mathrm{~N}_{2}$ mice were used to map the Igif locus (see text for details). DNA isolation, restriction enzyme digestion, agarose gel electrophoresis, Southern blot transfer, and hybridization were performed essentially as described in reference 14 . All blots were prepared with Hybond- $\mathrm{N}^{+}$nylon membrane (Amersham Corp., Arlington Heights, IL). The probe, an $\sim 572$ bp Eco RI fragment of mouse cDNA, was labeled with $\left[\alpha^{32} \mathrm{P}\right] \mathrm{dCTP}$ using a nick translation labeling kit (Boehringer Mannheim Biochemicals, Indianapolis, IN); washing was done to a final stringency of $0.8 \times \mathrm{SSCP}, 0.1 \% \mathrm{SDS}$ at $65^{\circ} \mathrm{C}$. A fragment of $3.8 \mathrm{~kb}$ was detected in Eco RI digested C57BL/6J DNA and a major fragment of $3.4 \mathrm{~kb}$ was detected in Eco RI digested M. spretus DNA. Presence or absence of the $3.4 \mathrm{~kb}$ Eco RI M. spretus-specific fragment was followed in backcross mice.

A description of the probes and RFLPs for the loci linked to Igif has been reported previously (15). Recombination distances were calculated as described using a computer program SPRETUS MADNESS (16). Gene order was determined by minimizing the number of recombination events required to explain the allele distribution patterns.

Histology. Diabetic animals were killed after diagnosis of hyperglycemia; normoglycemic animals were killed at the age of $95 \mathrm{~d}$. Pancreata were excised, cut in half longitudinally and half snap frozen in liquid nitrogen. Crystat sections were stained with heamatoxylineosin for evaluation of infiltrating immune cells by light microscopy.
A

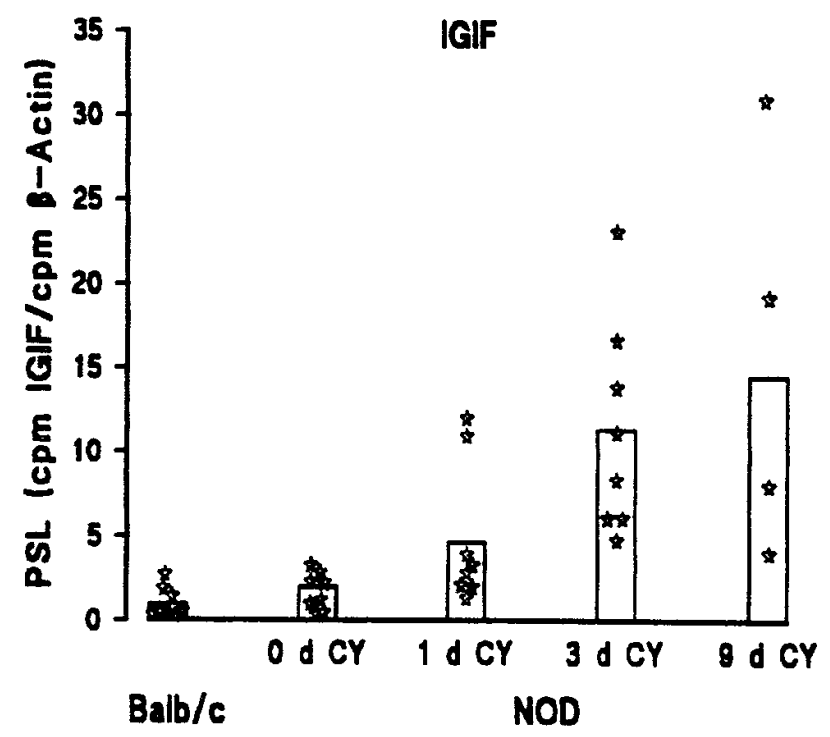

B

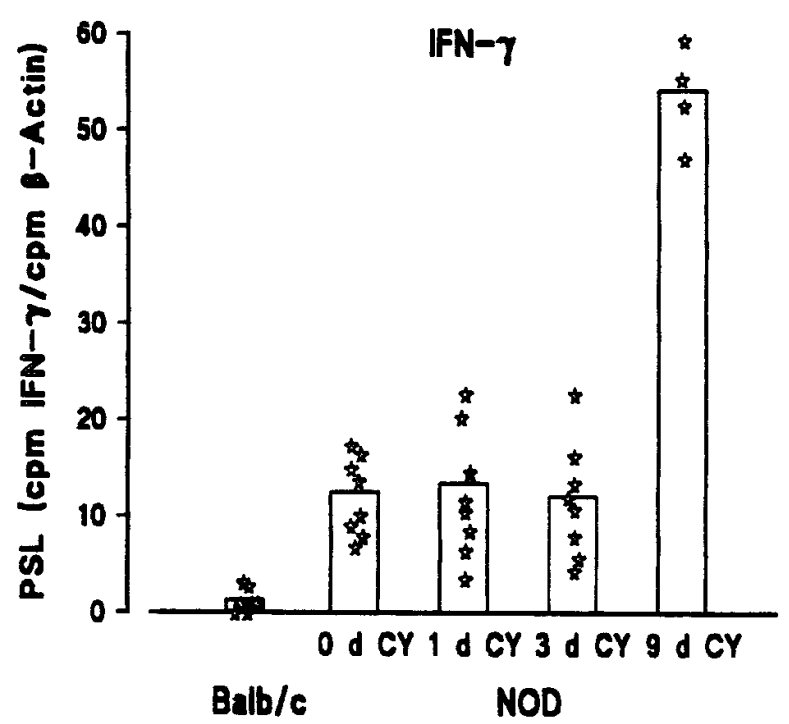

Figure 1. Kinetics of IGIF mRNA expression in pancreata of Balb/c and of NOD mice before and 1,3, and $9 \mathrm{~d}$ after CY treatment. $(A)$ Shown are the relative quantities of RT-PCR signal for IGIF as determined by ${ }^{32} \mathrm{P}$ stimulated luminescence followed by normalization to the signals of RT-PCR of $\beta$-actin mRNA of individual mice. The bars give the mean values of each group. $(B)$ Shown are the relative quantities of RT-PCR signal for IFN- $\gamma$ calculated as described above. The bars give the mean values of each group. 
Analysis was done from all islets in different sections at intervals of $100 \mu \mathrm{m}$, yielding a total of at least 10 islets per animal. Five grades of infiltration were defined: grade 0 : no periductular infiltrates and $<5$ immune cells peri- and intra-insular; grade 1: periductular infiltrates only; grade 2: periductular and peri-insular infiltrates only; grade 3 : intra-islet infiltration of less than $20 \%$ of the islet area; and grade 4 : intra-islet infiltration of more than $20 \%$ of islet area. Slides were coded and insulitis grades rated independently by two observers.

Statistical analysis. Mean radioactive signals of RT-PCR products were compared by Wilcoxon U-test, rank correlation assay of Spearman (R) or linear regression (r). Statistical analysis for incidence of diabetes and degree of insulitis was performed by $\mathrm{Chi}^{2}$-test.

\section{Results}

$C Y$ induced progression from peri- to intrainsulitis. At $70 \mathrm{~d}$ of age the analysis of the pancreas of six diabetes prone NOD mice (10 islets each) showed 16 islets with periinsulitis $(26.6 \%$, insulitis grades $1+2)$ and 43 islets with intrainsulitis $(71.6 \%$, insulitis grades $3+4)$. Substantial progression of insulitis was seen nine days after CY treatment. Nearly all islets exhibited an advanced insulitis grade $(91.6 \%)$ whereas periinsulitis was seen in $8.3 \%$ of 60 islets analyzed. Groups of 14 mice were prospectively tested for hyperglycemia. First cases of

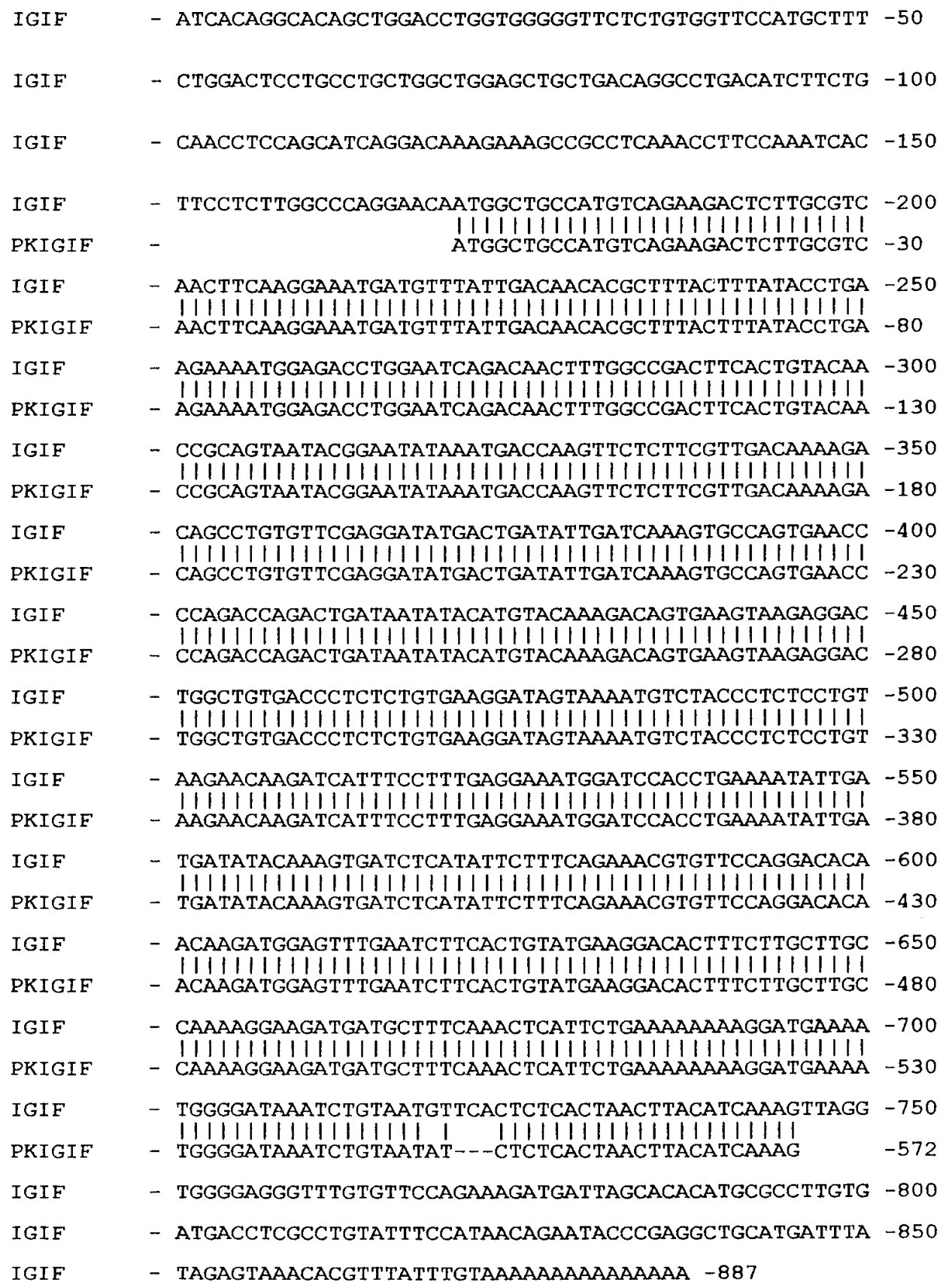

Identity : 571 (99.838)

Number of gaps inserted in IGIF: 0

Number of gaps inserted in PKIGIF: 1
Figure 2. DNA sequence comparison of the cloned IGIF cDNA of NOD pancreas mRNA (PKIGIF, accession number U66244) and the published IGIF sequence from liver. 
overt diabetes were observed at day 11 after CY, the total incidence by 21 days being $57 \%$. In the group not having received CY no animal developed diabetes.

IGIF $m R N A$ expression in the pancreas of NOD mice. Using amplification of mRNA by RT-PCR low levels of IGIF mRNA were detected in the pancreas prior to CY treatment. Also in untreated, healthy Balb/c control mice low levels of IGIF mRNA were detected in the pancreas (Fig. 1). After acceleration of the disease process by treatment with $\mathrm{CY}$ we detected a sixfold increase $(P<0.01, \mathrm{R}=0.994)$ of IGIF mRNA expression in the pancreas of NOD mice within the first $3 \mathrm{~d}$ after CY treatment (Fig. $1 A$ ). RT-PCR analysis of IGIF mRNA was repeated by varying the cycle number for IGIF mRNA amplification $(n=29,32,35)$ and for $\beta$-actin message amplification $(n=20,23,26,32)$. In none of the experiments was the increase of IGIF mRNA found to be less than fourfold. No further increase was observed in the following $6 \mathrm{~d}$. In contrast, a significant increase $(P<0.005, \mathrm{R}=0.998)$ of IFN- $\gamma$ mRNA was only seen at the later date (Fig. $1 B$ ), as described previously $(8,16)$. Hence, enhanced IGIF gene expression preceded IFN- $\gamma$ gene expression.

Cloning of IGIF cDNA from NOD pancreas RNA. In order to determine whether the IGIF-like mRNA was identical to authentic IGIF described in mouse liver, the cDNA was cloned from pancreas RNA of NOD mice $3 \mathrm{~d}$ after CY treatment. We obtained a 572-bp cDNA fragment and sequenced it in an automatic DNA sequencer. The resulting sequence was compared to the published IGIF cDNA cloned from activated Kupffer cells (1). Comparison of the sequences showed a $99.8 \%$ identity of the two sequences (Fig. 2). Our cloned cDNA of IGIF was 3 bp shorter than the published sequence and exhibited one basepair exchange. Both differences are located near the $3^{\prime}$-end of the coding region of the cDNA.

Chromosomal location of the IGIF gene. C57BL/6J and $M$. spretus DNA were digested with several enzymes and analyzed by Southern blot hybridization for informative RFLPs using a mouse cDNA Igif probe. The $3.4 \mathrm{~kb}$ Eco RI M. spretus was used to follow the segregation of the Igif locus and backcross mice. The mapping results indicated that Igif is located in the central region of mouse chromosome 9 linked to Thy1, Drd2, and Atm. Although 138 mice were analyzed for every marker and are shown in the segregation analysis (Fig. 3), up to 166 mice were typed for some pairs of marker. Each locus was analyzed in pairwise combinations for recombination frequencies using additional data. The ratios of the total number of mice exhibiting recombinant chromosomes to the total number in mice analyzed for each pair of loci, and the most likely gene order are: centromere: Thy1-2/162-Drd2-1/165-Igif-4/166Atm. The recombination frequencies (expressed as genetic distance in centiMorgans $[\mathrm{cM}] \pm$ the standard error) are: Thy1$1.2 \pm 0.9-$ Drd2 $-0.6 \pm 0.6-$ Igif-2.4 $\pm 1.2-$ Atm.

We have compared our interspecific map of chromosome 9 with a composite mouse linkage that reports the map location of many uncloned mouse mutations and markers (provided by Mouse Genome Database, a computerized database maintained at the Jackson Laboratory, Bar Harbor, ME). Igif mapped in a region of the composite map that contains a polygenic trait locus with a phenotype that might be expected for an alteration in this gene (data not shown). NOD mice carry several loci that confer susceptibility to insulin-dependent diabetes (17). One of these, $I d d 2$, maps to an approximately $20 \mathrm{cM}$ interval on mouse chromosome 9 (18).

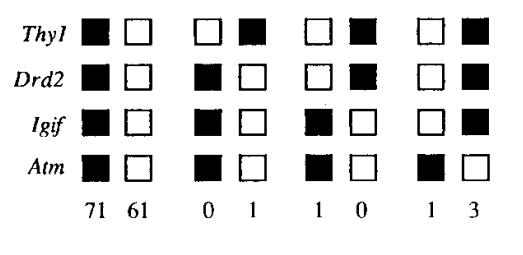

Figure 3. Igif maps in the central region of mouse chromosome 9 . Igif was placed on mouse chromosome 9 by interspecific backcross analysis. Segregation patterns of Igif and flanking genes in 138 backcross animals that were typed for all loci are shown at the top of the figure. For individual pairs of loci, more than 138 animals were typed (see text). Each column represents the chromosome identified in the backcross progeny that was inherited from $(\mathrm{C} 57 \mathrm{BL} / 6 \mathrm{~J} \times M$. spretus) $\mathrm{F}_{1}$ parent. The shaded boxes represent the presence of a

C57BL/6J allele and white boxes represent the presence of a $M$. spretus allele. The number of offspring inheriting each type of chromosome is listed at the bottom of each column. A partial chromosome 9 linkage map showing the location of Igif in relation to linked genes is shown at the bottom of the figure. Recombination distances between loci in centimorgans are shown to the left of the chromosome and the position of loci in human chromosomes, where known, are shown to the right. References or the human map positions of loci cited in this study can be obtained from Genome Data Base (GDB), a computerized database of human linkage information maintained by The William H. Welch Medical Library of The John Hopkins University (Baltimore, MD).

Finally, the central region of mouse chromosome 9 shares a region of homology with human chromosome 11q22-q23 (summarized in Fig. 3), suggesting that Igif will reside on $11 \mathrm{q} 22-\mathrm{q} 23$ as well.

IGIF $m$ RNA expression in spleen cells. We determined whether IGIF gene expression in response to $\mathrm{CY}$ treatment was confined to autoimmunity affected tissue or was a general property of the NOD mouse immune system. Spleen cells of NOD and Balb/c mice were analyzed. In NOD mice, $3 \mathrm{~d}$ after CY treatment, an eightfold increase of IGIF mRNA expression was found for the adherent spleen cell population $(P<$ 0.005, $\mathrm{R}=0.774$ ) (Fig. $4 A$ ). IGIF mRNA expression in spleen cells of Balb/c mice was minimal and not affected by $\mathrm{CY}$ treatment. At all points of time the nonadherent spleen cell population showed minimal expression of IGIF mRNA, which identifies macrophages as the major source of IGIF (Fig. $4 B$ ).

$I L-12$ versus IGIF $m R N A$ expression. A recent study described a rapid increase in IL-12p40 mRNA expression in the pancreas of NOD mice treated with CY within the first $3 \mathrm{~d}$, whereas the IL-12p35 subunit was constitutively expressed (9). Comparison of individual IGIF mRNA level with the corresponding IL-12p40 mRNA level showed strong correlation in untreated NOD mice $(r=0.976, P<0.001)$, as well as after CY treatment at day $1(r=0.96, P<0.001)$, day $3(r=0.877$, $P<0.003)$, and day $9(r=0.995, P<0.003)$ (Fig. 5). 
A

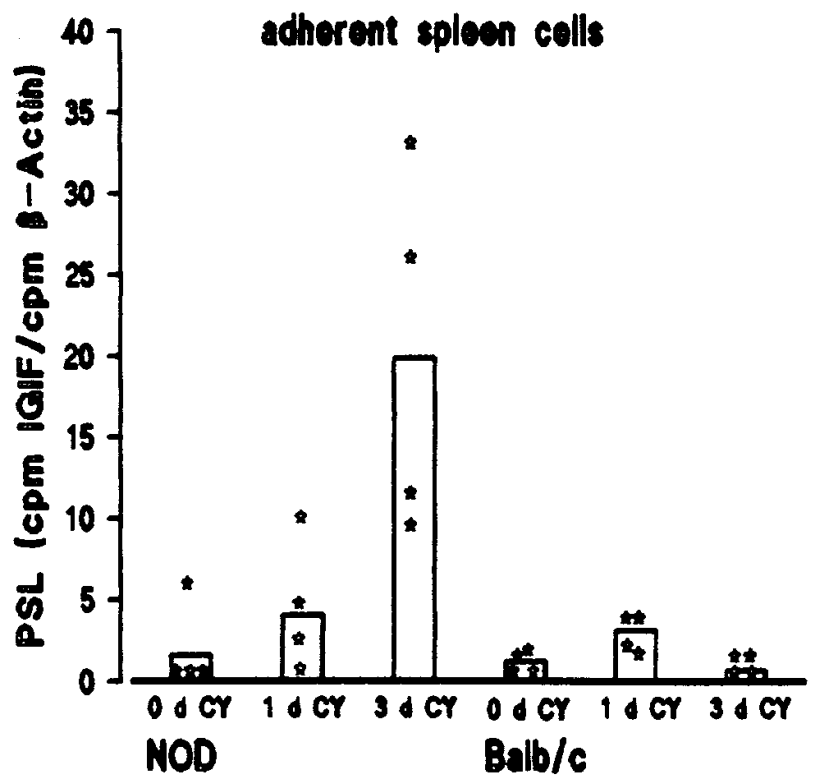

B

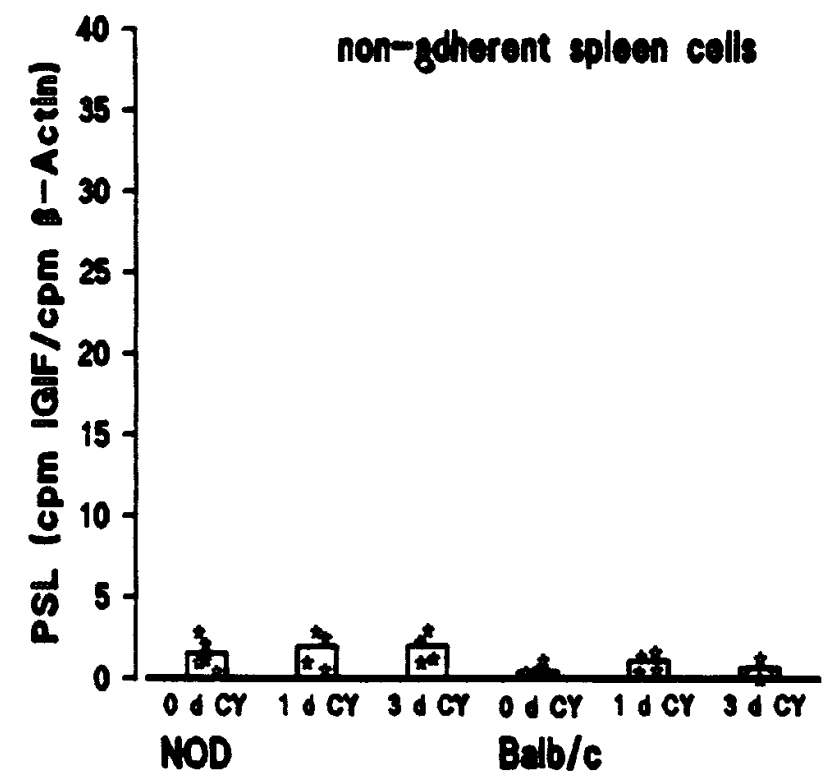

Figure 4. Kinetics of IGIF mRNA expression in adherent and nonadherent spleen cells. Shown are the relative quantities of RT-PCR signal for IGIF as determined by ${ }^{32} \mathrm{P}$ stimulated luminescence followed by normalization to the signals of RT-PCR of $\beta$-actin mRNA of individual mice. The bars give the mean values of each group. $(A)$ RT-PCR results of adherent spleen cells; $(B)$ RT-PCR results of nonadherent spleen cells.

\section{Discussion}

The data presented show for the first time an involvement of IGIF in autoimmune disease. IGIF gene expression was found to precede by a few days the active disease stage of autoimmune diabetes in NOD mice, characterized by mononuclear infiltration of the inner islet area (insulitis grades $3+4$ ) and IFN- $\gamma$ expression. Only low levels of IGIF mRNA were de-

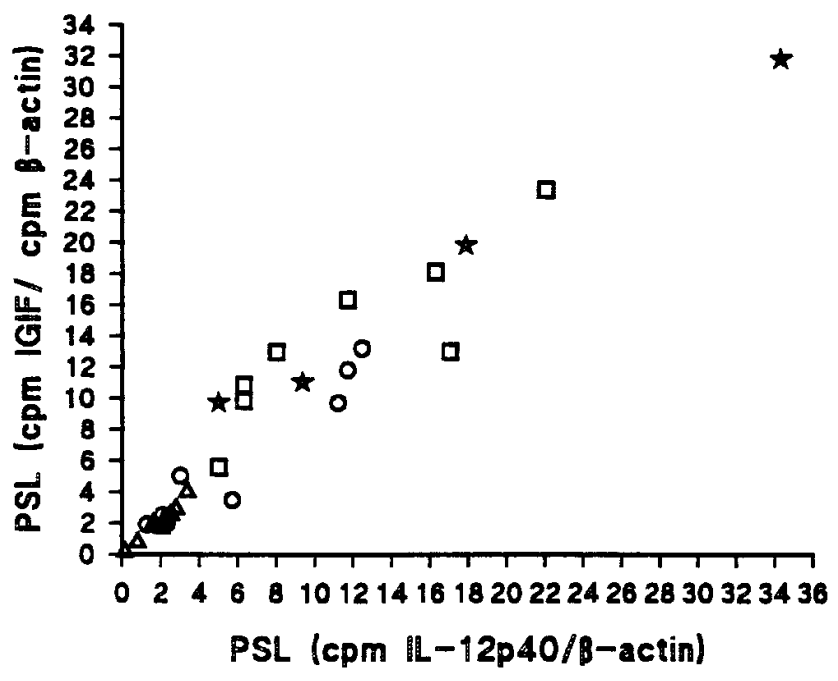

$$
\begin{array}{ll}
\triangle: \text { NOD O d CY } & \begin{array}{l}
\text { : NOD } 1 \mathrm{~d} C Y \\
\square: \text { NOD } 3 \mathrm{~d} C Y
\end{array}
\end{array}
$$

Figure 5. Correlation of individual IGIF and IL-12p40 mRNA expression in pancreas of NOD mice. Shown are the individual data of untreated NOD mice $(\triangle)$, and NOD mice $1 \mathrm{~d}(\bigcirc), 3 \mathrm{~d}(\square)$, and $9 \mathrm{~d}$ (饥) after treatment with $\mathrm{CY}$. tected in pancreata with early nondestructive stages of islet inflammation, i.e., periinsulitis. The rise of mRNA was determined by a semiquantitative RT-PCR method. Using the same method we observed previously a close correlation between a rise in IFN- $\gamma$ mRNA levels as determined by RT-PCR with an increase of IFN- $\gamma$ positive T cell numbers within islets, as determined by immunohistochemistry (5). In a parallel study of $\mathrm{BB}$ rats we observed a highly significant correlation of the individual islet score and RT-PCR determined mRNA levels of IFN- $\gamma$, IL-10, TGF $\beta$ and inducible nitric oxide synthase (12). These findings demonstrate a close relationship between cytokine mRNA levels detected and the disease process.

The rise of IGIF gene expression did not only precede Th1 insulitis in the pancreas but also occurred in parallel in the spleen indicating a systemic shift towards Th1 reactivity at the time of peak disease activity. IGIF mRNA was confined to the adherent cell population which identifies macrophages as its source.

It is important to note that IGIF gene expression did not occur in the context of general nonspecific activation of macrophages after CY treatment. First, macrophages of Balb/c mice did not respond to $\mathrm{CY}$ administration with IGIF expression. Second, earlier studies showed that two other markers of macrophage activation, $\mathrm{TNF}-\alpha$ and inducible nitric oxide synthase, only rise with delayed kinetics after $\mathrm{CY}$ administration, in parallel with IFN- $\gamma(5,8)$. This demonstrated abnormal control of IGIF gene transcription in NOD mouse macrophages. Regulatory defects of macrophages or antigen presenting cells have been suggested previously as essential conditions for the development of type I diabetes $(20,21)$.

The chromosomal location of Igif was determined by interspecific backcross analysis using progeny derived from matings of $[(\mathrm{C} 57 \mathrm{BL} / 6 \mathrm{~J} \times$ Mus spretus $) \mathrm{F} 1 \times \mathrm{C} 57 / 6 \mathrm{~J}]$ mice. This interspecific backcross mapping panel has been typed for over 
2,200 loci that are well distributed among all autosomes as well as the $\mathrm{X}$ chromosome (13). NOD mice carry several loci that confer susceptibility to insulin-dependent diabetes (18). One of these, Idd2, maps to an $\sim 20$-cM interval on mouse chromosome 9 (19). This interval includes Igif and our studies make Igif an attractive candidate for Idd2. The non-MHC IDDM susceptible gene region $I d d 2$ is associated with the acceleration of diabetes development (22). This observation would fit with a role of IGIF in during Th1 associated destructive insulitis. However, additional work is required to confirm the genetic association of IGIF with $\operatorname{Id} d 2$.

It is of interest that kinetics of IGIF expression resemble those of IL-12 (8) suggesting that both cytokines contribute to the surge of Th1 cells invading the core of islets. This is underlined by the strong correlation of IGIF and IL-12 mRNA expression at the level of individual animals. In this context, it is important to note that IL-12 and IGIF exhibit a strong synergistic effect on IFN- $\gamma$ production from Th1 cells (1). We conclude that the progression towards destructive Th1 insulitis begins in parallel with the production of the two IFN- $\gamma$ inducing mediators IGIF and IL-12 from APCs followed by recruitment and activation of Th1 cells. The local release of IFN- $\gamma$ and other Th1 cytokines in turn produce inflammatory mediators such as TNF- $\alpha$ and nitric oxide. Hence, it is expected that neutralization of either the two cytokines will have a profound suppressive effect on Th1 autoimmunity. For final proof of a driving role of IGIF, synergistically with IL-12, in cellular autoimmunity, the development of neutralizing monoclonal antibodies to IGIF and of gene-targeted mice has to be awaited. An alternative approach is to test for a potential disease accelerating effect of IGIF administrations. IGIF represents a promising target of diagnostic and therapeutic measures in autoimmune diseases.

\section{Acknowledgments}

We thank Michael Blendow and Mary Barnstead for their excellent technical assistance.

This work was supported by the Bundesminister für Gesundheit, by the Minister für Forschung und Wissenschaft des Landes Nordrhein-Westfalen, by the Deutsche Forschungsgemeinschaft, and by the National Cancer Institute, Division of Health and Human Services, under contract with ABL.

\section{References}

1. Okamura, H., H. Tsutsui, T. Komatsu, M. Yutsudo, A. Hakura, T. Tanimoto, K.Torigoe, T. Okura, Y. Nukada, K. Hattori, et al. 1994. Cloning of a new cytokine that induces IFN- $\gamma$ production by T cells. Nature (Lond.). 378:88-91.

2. Signore, A., E. Proccacini, A.M. Toscano, E. Ferretti, A.J. Williams, P.E. Beales, P. Cugini, and P. Pozzilli. 1995. Histological study of pancreatic beta cell loss in relation to the insulitis process in the non-obese diabetic mouse. Histochemistry. 101:263-269.

3. Bowman, M.A., E.H. Leiter, and M.A. Atkinson. 1994. Prevention of diabetes in the NOD mouse: implications for therapeutic intervention in human disease. Immunol. Today. 15:115-120.

4. Shehedeh, N.N., F. LaRosa, and K.J. Lafferty. 1993. Altered cytokine activity in adjuvant inhibition of autoimmune diabetes. J. Autoimmun. 6:291-300.

5. Rothe, H., A. Faust, U. Schade, R. Kleemann, G. Bosse, T. Hibino, S. Martin, and H. Kolb. 1994. Cyclophosphamide treatment of female non-obese diabetic mice causes enhanced expression of inducible nitric oxide synthase and interferon-gamma, but not (1993) interleukin-4. Diabetologia. 37:1154-1158.

6. Debray-Sachs, M., C. Carnaud, C. Boitard, H. Cohen, I. Gresser, P. Bedossa, and J.F. Bach. 1994. Prevention of diabetes in NOD mice treated with antibodies to murine IFN gamma. J. Autoimmun. 4:237-248 .

7. Katz, J.D., C. Benoist, D. Mathis. 1995. T helper cell subsets in insulindependent diabetes. Science (Wash. D.C.). 268:1185-1188.

8. Trinchieri, G. 1994. Interleukin-12: a cytokine produced by antigen-presenting cells with immunregulatory function in the generation of T-helper cells type I and cytotoxic lymphocytes. Blood. 48:4008-4027.

9. Rothe, H., V. Burkart, A. Faust, and H. Kolb. 1996. Interleukin-12 gene expression is associated with development of diabetes mellitus in non-obese diabetic mice. Diabetologia. 39:119-122.

10. Trembleau, S., G. Penna, E. Bosi, A. Mortara, M.K. Gately, and L. Adorini. 1995. Interleukin-12 administration induces T helper type I cells and accelerates autoimmune diabetes in NOD mice. J. Exp. Med. 181:817-821.

11. Trembleau, S., G. Penna, S. Gregori, J. Magram, M.K. Gately, and L. Adorini. 1996. The role of endogenous IL-12 in the development of spontaneous diabetes in NOD mice. Autoimmunity. 21:A087 (Abstr.).

12. Kolb, H., U. Wötz-Pargenstert, R. Kleemann, H. Rothe, P. Rowsell, F.W. Scott. 1996. Cytokine gene expression in BB rat pancreas: natural course and impact of bacterial vaccines. Diabetologia. In press.

13. Copeland, N.G., and N.A. Jenkins. 1991. Development and applications of a molecular genetc linkage map of the mouse genome. Trends. Genet. 7:113118.

14. Jenkins, N.A., N.G. Coleland, B.A. Taylor, and B.K. Lee. 1982. Organization, distribution, and stability of endogenous ecotropic murine leukemia virus DNA sequences in chromosomes of Mus musculus. J. Virol. 43:26-36.

15. Pecker, I., K.B. Avraham, D.J. Gilbert, K. Savitsky, G. Rotman, T. Fukao, E. Schröck, S. Hirotsune, D.A. Tagle, F.S. Collins, et al. 1996. Identification and chromosomal localization of Atm, the mouse homolog of the ataxiatelangiectasia gene. Genomics. 35:39-45.

16. Green, M.C. 1989. Catalog of mutant genes and polymorphic loci. In Genetic Variants and Strains of the Laboratory Mouse. M.F. Lyon and A.G. Searle, editors. Oxford University Press, New York. 12-403.

17. Campell, I.L., T.W.H. Kay, L. Oxbow, and L.C. Harrison. 1991. Essential role for interferon-gamma and interleukin-6 in autoimmune insulin-dependent diabetes in NOD/Wehi mice. J. Clin. Invest. 87:739-742.

18. Prochazka, M., E.H. Leiter, D.V. Serreze, and D.L Coleman. 1987. Three recessive loci required for insulin-dependent diabetes in nonobese diabetic mice. Science (Wash. D.C.). 237:286-289.

19. Imai K., and D.M. Kingsley. 1994. Mouse chromosome 9. Mammal. Genome. 5:S139-S153.

20. Kolb-Bachofen, V., and H. Kolb. 1989. A role for macrophages in the pathogenesis of type I diabetes. Autoimmunity. 3:145-155.

21. Serreze, D.V. 1993. Autoimmune diabetes results from genetic defects manifest by antigen presenting cells. FASEB J. 7:1092-1096.

22. McAleer, M.A., P. Reifsnyder, S.M. Palmer, M. Prochazka, J.M. Love, J.B. Copeman, E.E. Powell, N.R. Rodrigues, J.B. Prins and D.V. Serreze. 1995. Crosses of NOD mice with the related NON strain. A polygenic model for IDDM. Diabetes. 44:1186-1895. 